\title{
Resistance to infection of long-term cryopreserved human aortic valve allografts
}

\author{
Viola Steffen, MD, ${ }^{\text {a,b }}$ Georg Marsch, MD, ${ }^{\text {a }}$ Karin Burgwitz, ${ }^{\text {a,b }}$ Christian Kuehn, MD, PhD,,${ }^{\text {a,b }}$ and \\ Omke E. Teebken, MD, $\mathrm{PhD}^{\mathrm{a}}$
}

\begin{abstract}
Objective: To analyze the in vitro antimicrobial activity of 3 antibiotic regimens (group A, gentamicin-piperacillin-vancomycin-metronidazole-amphotericin B; group $\mathrm{B}$, gentamicin-piperacillin-flucloxacillin-metronidazole-amphotericin $\mathrm{B}$; and group $\mathrm{C}$, meropenem-vancomycin-tobramycin-colistin-amphotericin B) used in the processing of cryopreserved human ascending aortic tissue and aortic valves against Staphylococcus epidermidis and Staphylococcus aureus. The results were additionally compared with the infection resistance of cryopreserved ascending aortic tissue against Escherichia coli and Pseudomonas aeruginosa.
\end{abstract}

Materials: Each of 10 cryopreserved human allografts (CHAs) was divided into 25 pieces (separating aortic wall and valve). Eighteen segments were microbiologically tested, and 7 pieces underwent scanning electron microscopy. A bacterial solution ( $4 \mathrm{~mL}$; optical density, $0.20 \pm 0.02$ ) was used for contamination. After incubation, the optical density of the solution was measured. CHAs underwent sonication to release viable adherent bacteria. The number of attached bacteria was quantified by the colony forming units per square centimeter of CHA surface.

Results: Antibiotic regimen groups B and C were more efficient than group A in eradicating gram-positive organisms adherent to the aortic wall $(P<.001)$. Group $\mathrm{C}$ showed enhanced resistance against $E$ coli compared with group A or B $(P<.001)$, whereas group B appeared to be more effective against $P$ aeruginosa $(P<.001)$. With reference to each antibiotic regimen, ascending aortic tissue showed significantly less bacterial contamination with staphylococcal bacteria than valve grafts $(P \leq .01)$.

Conclusions: CHAs possess antibacterial activity despite long-term storage over 5 years. Antibiotic combinations applied during CHA processing have a significant influence on their infection resistance. Ascending aortic tissue shows a significantly enhanced bacterial resistance against staphylococcal bacteria compared with aortic valves. (J Thorac Cardiovasc Surg 2016;151:1251-9)

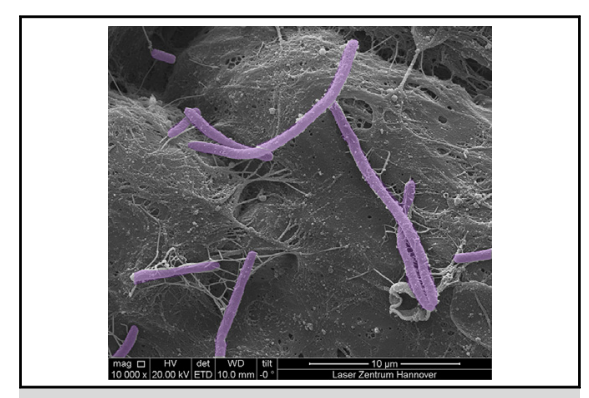

Elongated Escherichia coli on cryopreserved aortic wall allograft.

\section{Central Message}

The infection resistance of CHAs depends on antibiotic pretreatment and is superior in the aortic wall compared with valve tissue.

\section{Perspective}

Cryopreserved human allografts (CHAs) can be recommended to patients with destructive infections or high risk of (re)infection. Our in vitro study offers novel insight into the principles of antibacterial activity of CHAs. Enhanced retention of antibiotic agents may improve the infection resistance of CHAs. The risk of reinfection can be reduced by adapting the CHA decontamination protocol to the spectrum of infection-causing bacteria

See Article page 1239.

See Editorial Commentary page 1249.

See Editorial page 1230 .
Prosthetic graft infections are responsible for major morbidity and drastically increased mortality rates $(20 \%-80 \%)$ and therefore remain among the most challenging complications in cardiothoracic surgery. ${ }^{1-3}$

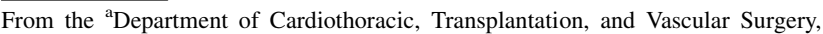
and ${ }^{\mathrm{b} C r o s s B I T}$ Research Center for Biocompatibility and Immunology of Medical Implants, Hannover Medical School, Hannover, Germany.

Funding sources: Internal funds.

Received for publication July 12, 2015; revisions received Oct 18, 2015; accepted for publication Nov 18, 2015; available ahead of print Dec 23, 2015

Address for reprints: Omke E. Teebken, MD, PhD, Department of Cardiothoracic, Transplantation, and Vascular Surgery, Hannover Medical School, Carl-Neuberg-

Str 1, OE 6210, 30625 Hannover, Germany (E-mail: Teebken.Omke@ MH-Hannover.de).

$0022-5223 / \$ 36.00$

Copyright (c) 2016 by The American Association for Thoracic Surgery

http://dx.doi.org/10.1016/j.jtcvs.2015.11.029
}

The incidence of prosthetic valve endocarditis ranges from $0.3 \%$ to $1.2 \%$ per patient year, with a cumulative risk of $5 \%$ at 10 years. ${ }^{1,2}$ Furthermore, $0.9 \%$ to $1.9 \%$ of patients develop a prosthetic graft infection following surgery on the thoracic aorta.

Most graft infections are caused by gram-positive bacteria, namely Staphylococcus aureus and Staphylococcus epidermidis. ${ }^{2,4}$ The increased incidence of highly

Scanning this QR code will take you to the article title page.

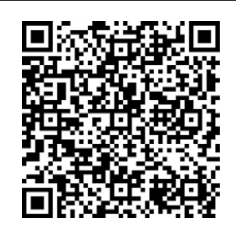




\section{Abbreviations and Acronyms \\ CHA = cryopreserved human allograft \\ $\mathrm{OD}_{600 \mathrm{~nm}}=$ optical density \\ PBS $=$ phosphate-buffered saline \\ SEM = scanning electron microscopy}

virulent and antibiotic-resistant microorganisms such as Pseudomonas aeruginosa and methicillin-resistant Staphylococcus aureus (MRSA) additionally hinders a successful eradication of infection, and consequently, investigations into this problem are currently ongoing., ${ }^{2,6}$

Various therapies for prosthetic graft infections involving the aortic valve and the ascending aorta have been described; for example, adaptive antibiotic treatment, antiseptic irrigation, and perhaps most importantly, surgical debridement. ${ }^{2,7}$ Because extra-anatomical rerouting is not possible at the site of the aortic root and the arch, surgical options involve either salvaging the existing graft by aggressive debridement, irrigation, and coverage with healthy tissue ${ }^{8}$ or graft removal and renewed in situ replacement with synthetic grafts or biological tissue; for example, cryopreserved human allografts (CHAs)., ${ }^{7-12}$

$\mathrm{CHAs}$ represent effective alternatives for the treatment of infections, with extremely low reinfection rates. ${ }^{13}$ Native and prosthetic valve endocarditis, ${ }^{12,14,15}$ as well as vascular prosthetic infections, ${ }^{6}$ show promising outcomes after CHA replacement. Furthermore, CHAs appear to be effective even in complex destructive infections involving the aortic root or ascending aorta., ${ }^{5,16}$ CHAs are not recommended for routine aortic valve or ascending aortic surgery, but can be considered for patients with destructive infections or high risk of (re)infection. ${ }^{17}$

The reason why CHAs exhibit this clinically observable bacterial resistance remains unclear, but may be related to their viability, which allows an improved transfer of antibiotic agents and immunocompetent cells through the wall into the perigraft space. ${ }^{18}$ Moreover, their antimicrobial activity might be attributed to processing and, in particular, to the storage of CHAs in antibiotics. ${ }^{19}$ However, this topic remains poorly investigated to date.

The aim of this in vitro study was to evaluate the antimicrobial activity of CHAs, taking a closer look at 3 clinically approved antibiotic regimens used in the processing of human ascending aortic tissue and aortic valves with respect to $S$ epidermidis and $S$ aureus, as gram-positive pathogens. Additionally, we compared these data with the infection resistance of cryopreserved ascending aortic tissue against gram-negative pathogens; for example, E coli and $P$ aeruginosa. We hypothesized that the choice of antibiotics has significant influence on infection resistance, and that valve and aortic wall tissue behave in a different manner.

\section{MATERIALS AND METHODS \\ Bacterial Strains}

The strains were 20044DSMZ for $S$ epidermidis, 20231DSMZ for $S$ aureus, 1103DSMZ for E coli, and 0411208MDPA01 for P aeruginosa. Isolates were subcultured overnight in tryptic soy broth (Oxoid, Hampshire, United Kingdom). The bacterial concentration measured by optical density $\left(\mathrm{OD}_{600 \mathrm{~nm}}\right)$, as used for graft contamination, amounted to $0.20 \pm 0.02$. This $\mathrm{OD}_{600 \mathrm{~nm}}$ corresponded to $6 \times 10^{7} \mathrm{CFU} / \mathrm{mL}$ for $S$ epidermidis, $8 \times 10^{7} \mathrm{CFU} / \mathrm{mL}$ for $S$ aureus, $3 \times 10^{6} \mathrm{CFU} / \mathrm{mL}$ for $E$ coli, and $3 \times 10^{6} \mathrm{CFU} / \mathrm{mL}$ for $P$ aeruginosa.

\section{CHAs}

Ten aortic valve allografts, including a segment of the ascending aorta, were obtained from the Deutsche Gesellschaft für Gewebetransplantation or its predecessor DSO-G. These allografts were rejected for transplantation because their storage time had exceeded 5 years. CHAs were subjected to the standard procedure of processing, consisting of harvesting from multiorgan donors, preparation, antibiotic treatment, cryopreservation, and thawing as described previously. ${ }^{6}$ The CHAs were assigned to three groups according to their antibiotic treatment (Table 1): group A (gentamicin, piperacillin, vancomycin, metronidazole, and amphotericin B), group B (gentamicin, piperacillin, flucloxacillin, metronidazole, and amphotericin $\mathrm{B}$ ), and group $\mathrm{C}$ (meropenem, vancomycin, tobramycin, colistin, and amphotericin B).

\section{Experimental Protocol}

Each CHA was divided into 25 pieces under sterile conditions as illustrated in Figure 1. The valves were dissected into 7 samples $\left(0.75 \mathrm{~cm}^{2}\right.$ or approximately $0.4 \mathrm{~cm}^{2}$ for controls). The wall specimens $\left(1 \mathrm{~cm}^{2}\right)$ were contaminated with both gram-positive and gram-negative microorganisms, whereas the cusps were incubated with the bacteria most frequently responsible for prosthetic valve endocarditis: $S$ epidermidis and S aureus. ${ }^{4}$ In detail, the piece of CHA (aortic wall or cusp) was placed into $4 \mathrm{~mL}$ subcultured bacterial suspension $\left(\mathrm{OD}_{600 \mathrm{~nm}}, 0.20 \pm 0.02\right)$ and incubated at $37^{\circ} \mathrm{C}$ and $5 \%$ carbon dioxide for 24 hours $(n=21)$. Two specimens of the aortic wall and 2 of the valve were incubated in sterile tryptic soy broth and served as controls.

Microbiologic tests. Following incubation, all grafts were washed 3 times in $50 \mathrm{~mL}$ phosphate-buffered saline (PBS) (Dulbecco; Biochrom, Berlin, Germany) to eliminate unattached bacteria. The $\mathrm{OD}_{600 \mathrm{~nm}}$ of the bacterial suspension was measured to evaluate bacterial growth in the surroundings of the specimens. The samples were transferred into sterile Falcon tubes containing $5 \mathrm{~mL}$ PBS, and the remaining viable adherent bacteria were released by sonication at low power $\left(37^{\circ} \mathrm{C}, 100 \%\right)$ for 20 minutes. ${ }^{20}$ $100 \mu \mathrm{L}$ of this PBS-solution containing the dislodged bacteria was plated onto tryptic soy broth-agar plates. All plates were incubated $\left(37^{\circ} \mathrm{C} ; 5 \%\right.$ carbon dioxide), and colonies were visually identified and counted with a Molecular Imager (Gel-Doc XR; Bio-Rad Laboratories, Munich, Germany). The results were used to determine the number of attached bacteria per square centimeter of CHA surface.

Scanning electron microscopy. After incubation, each sample was washed three times in PBS to remove unattached microorganisms. Samples were subsequently fixed in a $2.5 \%$ glutaraldehyde and sodium-cacodylate buffer ( $0.1 \mathrm{M}$; pH 7.3), after which they were passed through an increasing concentration of acetone before dehydration in a critical point dryer (CPD-030; Bal-Tec GmbH, Balzers, Liechtenstein), sputtered with gold, and observed by scanning electron microscopy (SEM) (Quanta-400F; FEI Company, Hillsboro, Ore), at $20 \mathrm{kV}$ and a resolution of $1 \mathrm{~nm}$.

\section{Statistical Analysis}

All data are expressed as mean \pm standard error of the mean. The Mann-Whitney test was chosen to compare the different groups. SPSS version 21.0 (IBM-SPSS Inc, Armonk, NY) and GraphPad Prism version 
TABLE 1. Characteristics of the cryopreserved human allografts (CHAs)

\begin{tabular}{lcccc}
\hline $\begin{array}{c}\text { CHA antibiotic } \\
\text { group* }\end{array}$ & $\begin{array}{c}\text { Donor } \\
\text { age (y) }\end{array}$ & $\begin{array}{c}\text { Donor } \\
\text { sex }\end{array}$ & $\begin{array}{c}\text { Donor } \\
\text { AB0-type }\end{array}$ & $\begin{array}{c}\text { Duration of } \\
\text { cryopreservation (y) }\end{array}$ \\
\hline A & 18 & F & B & 7.42 \\
& 18 & F & AB & 8.19 \\
& 36 & F & AB & 8.79 \\
B & 62 & F & 0 & 9.09 \\
& 12 & M & AB & 9.17 \\
& 40 & F & 0 & 9.64 \\
& 14 & F & 0 & 9.81 \\
& 30 & M & 0 & 10.00 \\
C & 29 & M & AB & 6.49 \\
& 12 & M & A & 6.61 \\
\hline
\end{tabular}

*Group A includes gentamicin, piperacillin, vancomycin, metronidazole, and amphotericin B. Group B includes gentamicin, piperacillin, flucloxacillin, metronidazole, and amphotericin B. Group C includes meropenem, vancomycin, tobramycin, colistin, and amphotericin B.

5.0 for Windows (GraphPad Software Inc., San Diego, Calif) software packages were used. The study was approved by the local ethics committee (reference No. 1008/2011).

\section{RESULTS}

The average storage time of CHAs was 8.52 years (range, 6.49-10.0 years) (Table 1). Macroscopic examination revealed no apparent structural deficiencies.

\section{Microbiologic Tests}

Aortic wall, $S$ epidermidis, and $S$ aureus. As shown in Figures 2 and 3, after incubation with $S$ epidermidis, $1.0 \times 10^{5} \pm 2.4 \times 10^{4} \mathrm{CFU} / \mathrm{cm}^{2}$ were found on the samples of group A. This was higher $(P<.001)$ than the number of bacteria found on the specimens of group $B$ $\left(1.3 \times 10^{1} \pm 9.4 \times 10^{0} \mathrm{CFU} / \mathrm{cm}^{2}\right)$ or on the tissue of group $\mathrm{C}\left(8.8 \times 10^{1} \pm 4.4 \times 10^{1} \mathrm{CFU} / \mathrm{cm}^{2}\right)$. The $\mathrm{OD}_{600 \mathrm{~nm}}$ of the supernatant showed comparable results (Table 2).

After incubation with $S$ aureus, we found $9.4 \times 10^{2} \pm$ $1.6 \times 10^{2} \mathrm{CFU} / \mathrm{cm}^{2}$ on the tissue of group A. This was significantly $(P<.001)$ more than that found on the samples of group B $\left(1.6 \times 10^{2} \pm 4.1 \times 10^{1} \mathrm{CFU} / \mathrm{cm}^{2}\right)$ or in group C $\left(8.3 \times 10^{0} \pm 5.3 \times 10^{0} \mathrm{CFU} / \mathrm{cm}^{2}\right)$. No significant difference was apparent between groups $\mathrm{B}$ and $\mathrm{C}$ $(P=.083)$. Again, the $\mathrm{OD}_{600 \mathrm{~nm}}$ produced corresponding results (Table 2). Both gram-positive bacteria showed significantly increased colony forming units/centimeters ${ }^{2}$ and $\mathrm{OD}_{600 \mathrm{~nm}}$ for the aortic wall grafts stored in the antibiotics of group A.

Aortic valve, $S$ epidermidis, and $\boldsymbol{S}$ aureus. As shown in Figure 2, we found $2.3 \times 10^{5} \pm 4.3 \times 10^{3} \mathrm{CFU} / \mathrm{cm}^{2}$ attached to the cusps of group A after incubation with $S$ epidermidis. Grafts of group B exhibited $2.6 \times 10^{5}$ $\pm 5.7 \times 10^{3} \mathrm{CFU} / \mathrm{cm}^{2}$, whereas $1.6 \times 10^{5} \pm$ $7.4 \times 10^{3} \mathrm{CFU} / \mathrm{cm}^{2}$ were detected on the samples of group C. The number of adherent bacteria in group $\mathrm{C}$ was significantly smaller compared with group A $(P=.010)$ or B $(P=.002)$. After incubation with $S$ aureus we found a smaller amount of bacteria $\left(8.2 \times 10^{4} \pm 2.2 \times 10^{4} \mathrm{CFU} /\right.$ $\mathrm{cm}^{2}$ ) attached to the grafts of group B in comparison with group A $\left(2.0 \times 10^{5} \pm 1.4 \times 10^{4} \mathrm{CFU} / \mathrm{cm}^{2} ; P<.001\right)$. No significant difference was apparent between groups $\mathrm{B}$ and $\mathrm{C}\left(1.1 \times 10^{5} \pm 9.0 \times 10^{3} \mathrm{CFU} / \mathrm{cm}^{2} ; P=.945\right)$. Overall,

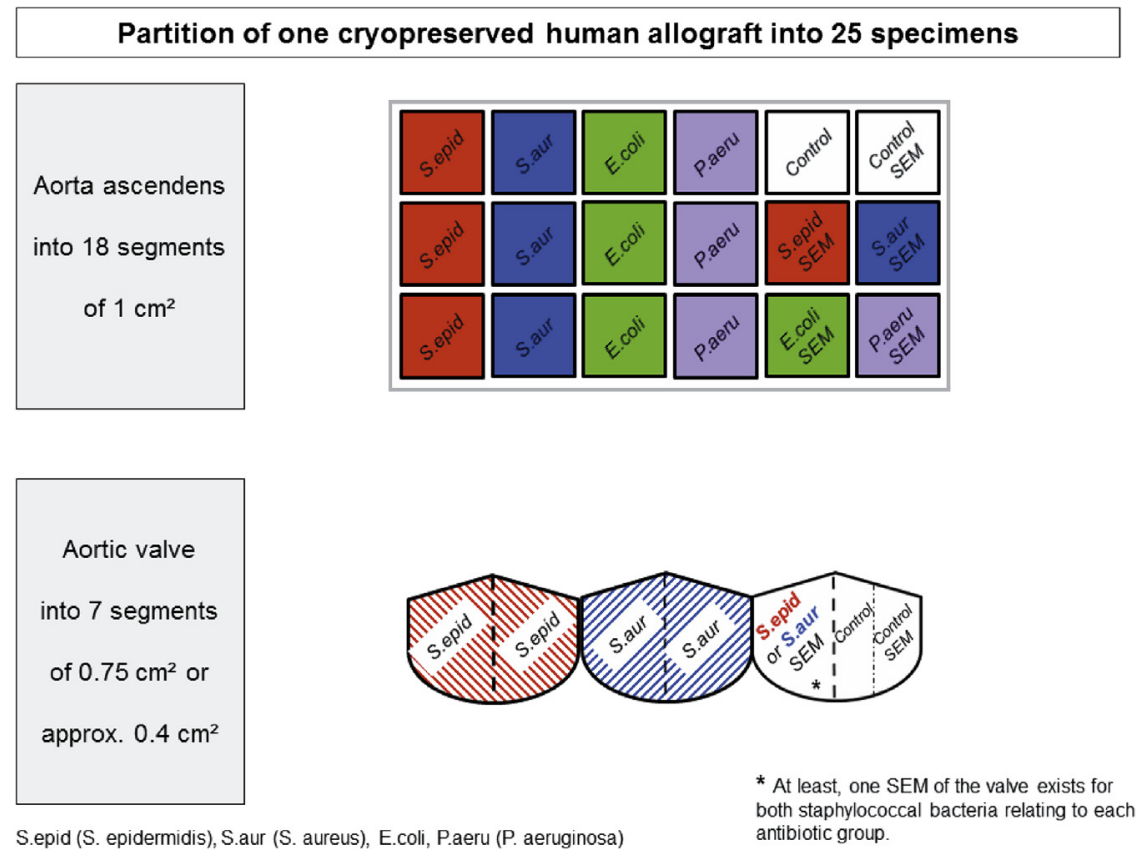

FIGURE 1. Partition of 1 cryopreserved human allograft for microbiologic experiments and tissue examination. S. epid, Staphylococcus epidermis; S. aur, Staphylococcus aureus; E. coli, Escherichia coli; P. aeru, Pseudomonas aeruginosa; SEM, scanning electron microscopy. 


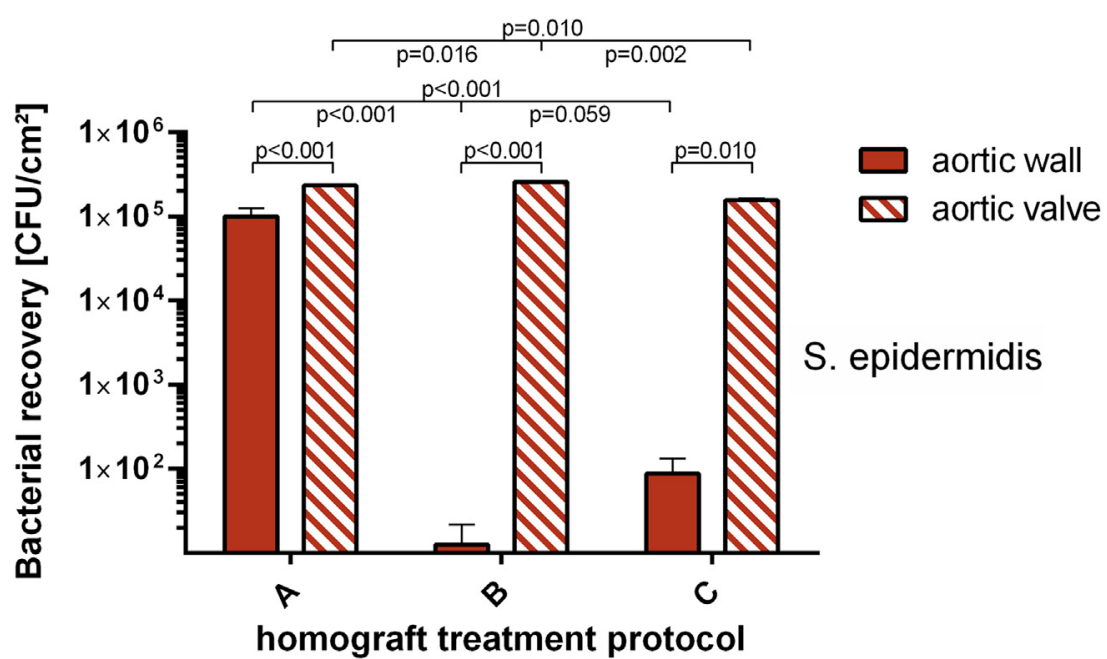

A

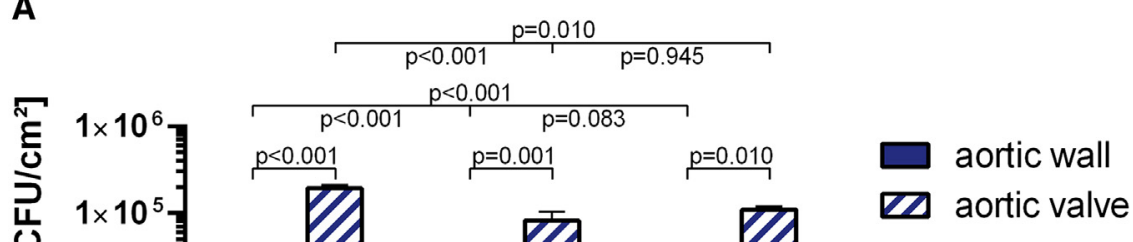

B homograft treatment protocol

FIGURE 2. Bacteria (colony forming units/centimeter ${ }^{2}$ ) adherent to aortic wall or valve tissue after antibiotic treatment according to protocol A through C and after incubation with A, Staphylococcus epidermidis (S. epidermis) or B, Staphylococcus aureus (S. aureus).

the difference between the aortic wall and valve was reflected in the significantly increased amounts of bacteria adherent to the valve for $S$ epidermidis and for $S$ aureus within each antibiotic group (both $P$ values $\leq .01$ ). This difference was also detected in the $\mathrm{OD}_{600 \mathrm{~nm}}$ (both $P$ values $<.01)$.

Aortic wall, $\boldsymbol{E}$ coli, and $\boldsymbol{P}$ aeruginosa. As shown in Figure 3, after incubation with $E$ coli, we found a smaller amount of bacteria $\left(1.2 \times 10^{3} \pm 5.6 \times 10^{2} \mathrm{CFU} / \mathrm{cm}^{2}\right)$ on the samples of group $\mathrm{C}$ in comparison with group $\mathrm{A}$ $\left(5.3 \times 10^{3} \pm 3.3 \times 10^{2} \mathrm{CFU} / \mathrm{cm}^{2}\right)$ or group $\mathrm{B}$ $\left(9.6 \times 10^{3} \pm 9.2 \times 10^{2} \mathrm{CFU} / \mathrm{cm}^{2} ; P<.001\right.$, respectively $)$. The $\mathrm{OD}_{600 \mathrm{~nm}}$ showed corresponding results. $P$ aeruginosa was most abundant on the grafts of group A $\left(4.4 \times 10^{4} \pm 3.2 \times 10^{3} \mathrm{CFU} / \mathrm{cm}^{2}\right)$ and showed a significant difference from the amount found in group $\mathrm{B}$ $\left(8.8 \times 10^{3} \pm 1.2 \times 10^{3} \mathrm{CFU} / \mathrm{cm}^{2} ; P<.001\right)$ or group $\mathrm{C}$ $\left(2.4 \times 10^{4} \pm 2.5 \times 10^{3} \mathrm{CFU} / \mathrm{cm}^{2} ; P=.001\right)$. In contrast, the $\mathrm{OD}_{600 \mathrm{~nm}}$ of the supernatants from group $\mathrm{A}$ was lower than that from the grafts of groups B and C (Table 2). In both investigations, group B exhibited low bacterial growth and a small number of adherent bacteria.

\section{SEM}

Representative pictures of CHAs impregnated with antibiotic agents according to protocol $\mathrm{A}$ through $\mathrm{C}$ and after bacterial incubation are illustrated in Figures 4 and 5 . Concerning the controls of groups A through $\mathrm{C}$, aortic vessels were partially covered with cells that were arranged according to blood flow. An intact endothelium was not detectable because wide areas presented irregularities in the morphology of cells, shrinkage with disruption of intercellular contacts, and observable stripping of the endothelium, exposure of the basal lamina, and partially damaged subendothelial layers (Figure 4, A). On the aortic valve, the spectrum of changes ranged from a smooth 


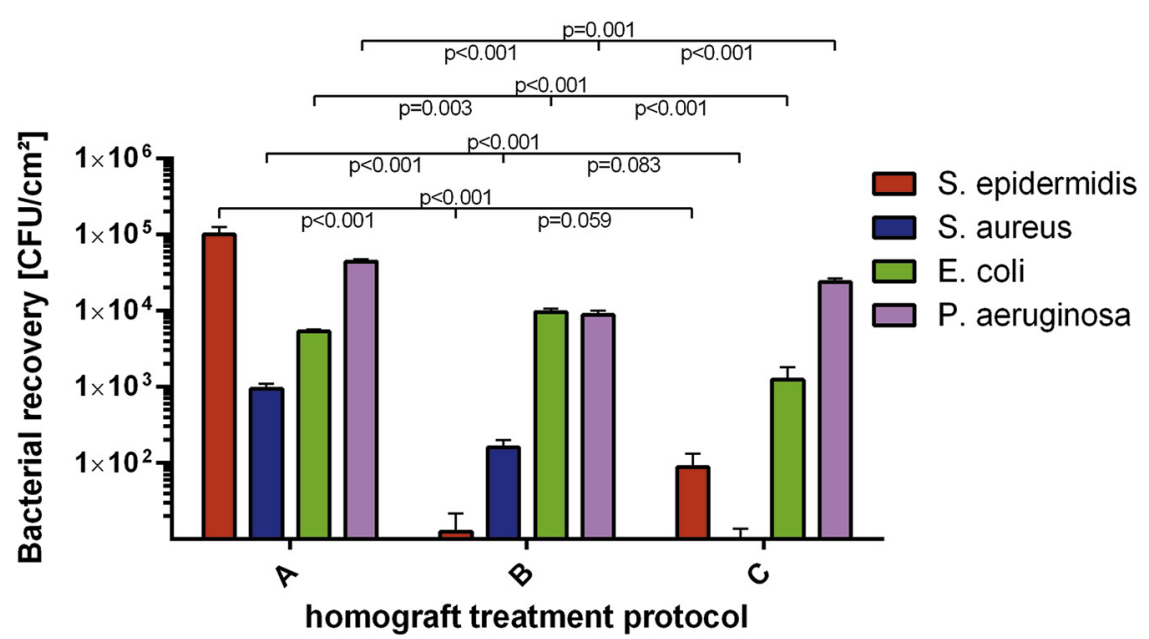

FIGURE 3. Bacteria (colony forming units/centimeters ${ }^{2}$ ) adherent to aortic wall tissue after antibiotic treatment according to protocol A through $\mathrm{C}$ and after bacterial incubation. S. epidermis, Staphylococcus epidermis; S. aureus, Staphylococcus aureus; E. coli, Escherichia coli; P. aeruginosa, Pseudomonas aeruginosa.

surface consisting of an exposed basal lamina to stripped endothelial cells with patches of damaged subendothelial layers. The continuity of endothelial coverage was lost on cusps (Figure 5, $A$ ).

Concerning gram-positive microorganisms on the aortic wall specimens, only a few adherent bacteria were observed, reflecting the results of the $\mathrm{OD}_{600 \mathrm{~nm}}$ and colony forming units/centimeters ${ }^{2}$ measurements (Figure 4, $B$ and $C$ ). Noticeably, and in concordance with the microbiologic examinations, extensive adherence of $S$ epidermidis was seen in group A.

In contrast, the valves were completely colonized with both staphylococcal bacteria, as seen in Figure 5, $B$ and $C$. A comparison of the three antibiotic treatments nonetheless revealed differences in the density of bacterial contamination.

With regard to the gram-negative microorganisms, we observed a characteristic network composed of the microorganisms and partially altered bacterial growth. The rod-shaped $E$ coli of $2 \mu \mathrm{m}$ in size were considerably elongated with a filamentous morphology, stretched by $>10 \mu \mathrm{m}$ (Figure $4, D$ ).

\section{DISCUSSION}

CHAs are well-known for their excellent hemodynamic characteristics, their decreased thromboembolic rate while avoiding the need for anticoagulation, and their infection resistance. $^{13,14,21}$ In this study, the infection resistance of CHAs previously treated with various antibiotic solutions was investigated.

Tissue banks rely on antibiotic agents during CHA processing, but their protocols differ significantly. ${ }^{22}$ The main objective is the decontamination of tissue to prevent bacterial transmission to allograft recipients without compromising tissue integrity. ${ }^{22}$ Previous studies have indicated that residual concentrations of these antibiotics are still present and effective in CHAs after preparation for implantation. ${ }^{23,24}$ Jashari and colleagues $^{24}$ investigated residual antibiotic concentrations in cryopreserved heart valves previously treated with vancomycin, lincomycin, and polymyxin B. Only residues of vancomycin and lincomycin were detected in the allografts, but the concentrations were largely below their therapeutic doses. ${ }^{24}$ Nevertheless, the authors did not measure the toxic effect on microorganisms. Furthermore, Buzzi and colleagues ${ }^{23}$

TABLE 2. Optical density in the supernatant of cryopreserved human allograft after antibiotic treatment according to protocol A through C and after bacterial incubation

\begin{tabular}{|c|c|c|c|c|c|c|}
\hline \multirow{2}{*}{ Antibiotic group } & \multirow[b]{2}{*}{$\mathbf{A}$} & \multirow{2}{*}{$\begin{array}{c}P \text { value } \\
\text { A-B }\end{array}$} & \multicolumn{3}{|c|}{$P$ value } & \multirow{2}{*}{$\begin{array}{r}P \text { valu } \\
\text { A-C }\end{array}$} \\
\hline & & & B & B-C & C & \\
\hline \multicolumn{7}{|l|}{ Aortic wall } \\
\hline Staphylococcus epidermidis & $1.54 \pm 0.10$ & $<.001$ & $0.07 \pm 0.01$ & $<.001$ & $0.13 \pm 0.01$ & $<.001$ \\
\hline Staphylococcus aureus & $0.31 \pm 0.03$ & .030 & $0.20 \pm 0.02$ & .203 & $0.14 \pm 0.02$ & .001 \\
\hline Escherichia coli & $1.79 \pm 0.02$ & .689 & $1.83 \pm 0.03$ & .001 & $1.46 \pm 0.09$ & .007 \\
\hline Pseudomonas aeruginosa & $0.24 \pm 0.02$ & .639 & $0.25 \pm 0.02$ & $<.001$ & $0.54 \pm 0.03$ & $<.001$ \\
\hline \multicolumn{7}{|l|}{ Valve tissue } \\
\hline Staphylococcus epidermidis & $2.07 \pm 0.03$ & .022 & $1.75 \pm 0.08$ & .240 & $1.56 \pm 0.10$ & .010 \\
\hline Staphylococcus aureus & $1.52 \pm 0.17$ & .042 & $1.02 \pm 0.13$ & .002 & $1.62 \pm 0.03$ & 1.000 \\
\hline
\end{tabular}



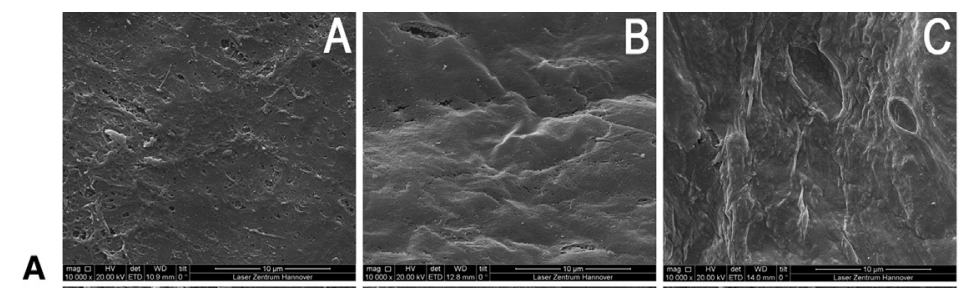

Control

A
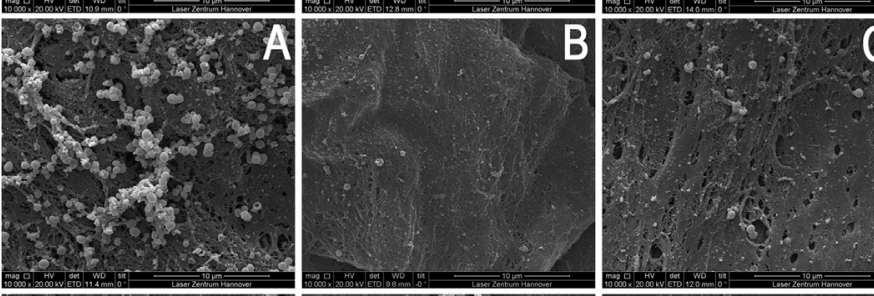

S. epidermidis
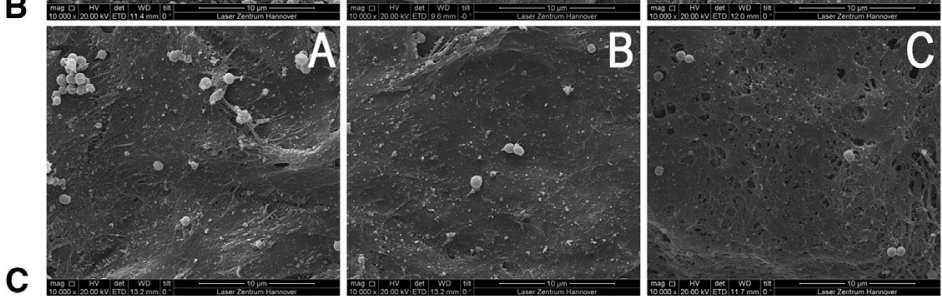

\section{.}

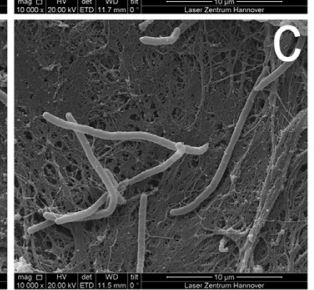

S. aureus
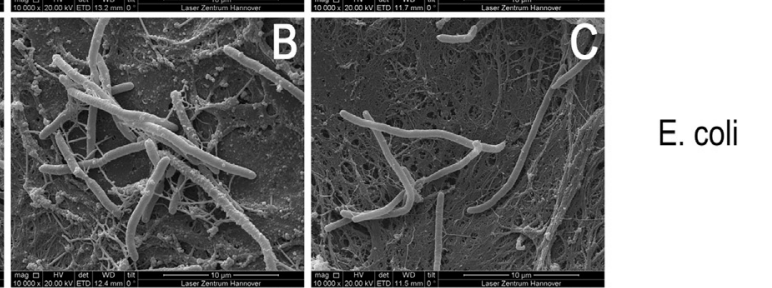

D
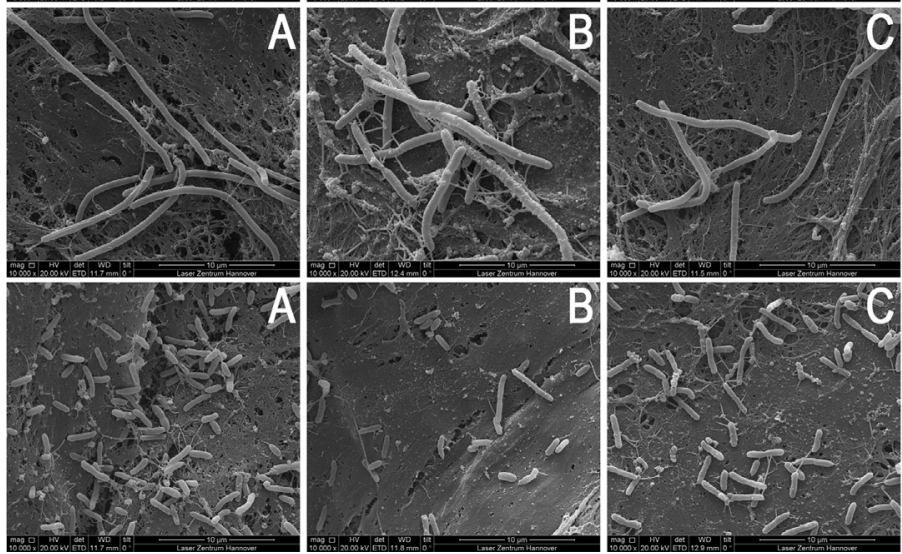

E. coli

\section{P. aeruginosa}

E

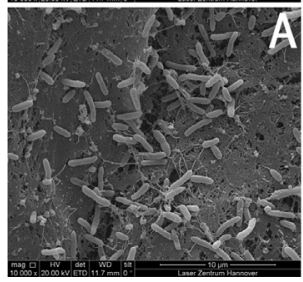

FIGURE 4. A, Cryopreserved aortic wall tissue after antibiotic treatment according to protocol A through $\mathrm{C}$ and after incubation with A, control, B, Staphylococcus epidermis (S. epidermidis), C, Staphylococcus aureus (S. aureus), D, Escherichia coli (E. coli), or E, Pseudomonas aeroginosa (P. aeruginosa).

demonstrated the effectiveness of residual antibiotics in cryopreserved human aortic heart valves and blood vessels by microbiologic examination, namely an agar diffusion test. After being thawed, CHA tissue revealed important inhibition zones on plates seeded with $S$ aureus and $P$ aeruginosa. ${ }^{23}$ Nevertheless, the period of cryopreservation remained unclear and the authors did not differentiate between heart valve and vessel tissue. This study confirmed indirectly the presence of residual antibiotics in cryopreserved tissue. Analyses of residual concentrations of antibiotics in long-term CHAs are still lacking, but several studies have shown that antibiotics are stable and potent after long-term storage at $-80^{\circ} \mathrm{C}$ for 180 days and longer. ${ }^{25,26}$

Our results support the hypothesis that infection resistance of CHAs depends on the antibiotic pretreatment during processing and their residual activity.
First, we found an important difference between the infection resistance of aortic wall and valve tissue. Irrespective of the antibiotic treatment applied during processing, significantly more staphylococcal bacteria were adherent to the cusps in comparison with the aortic wall (Figure 2). This difference was also reflected in the $\mathrm{OD}_{600 \mathrm{~nm}}$ and in representative SEM images (Figures 4 and 5). The findings suggest that the retention of the antibiotics is insufficient to prevent bacterial colonization of cusps, whereas the remaining antibiotics in the aortic wall specimens offer increased infection resistance. We used the same inoculum for aortic wall samples and for the thinner samples of the valve. Therefore, the latter is likely to contain fewer antibiotics and thus exhibits limited regional antibiotic release.

Second, regarding the aortic wall specimens, we found a significantly increased adherence of $S$ epidermidis in group 

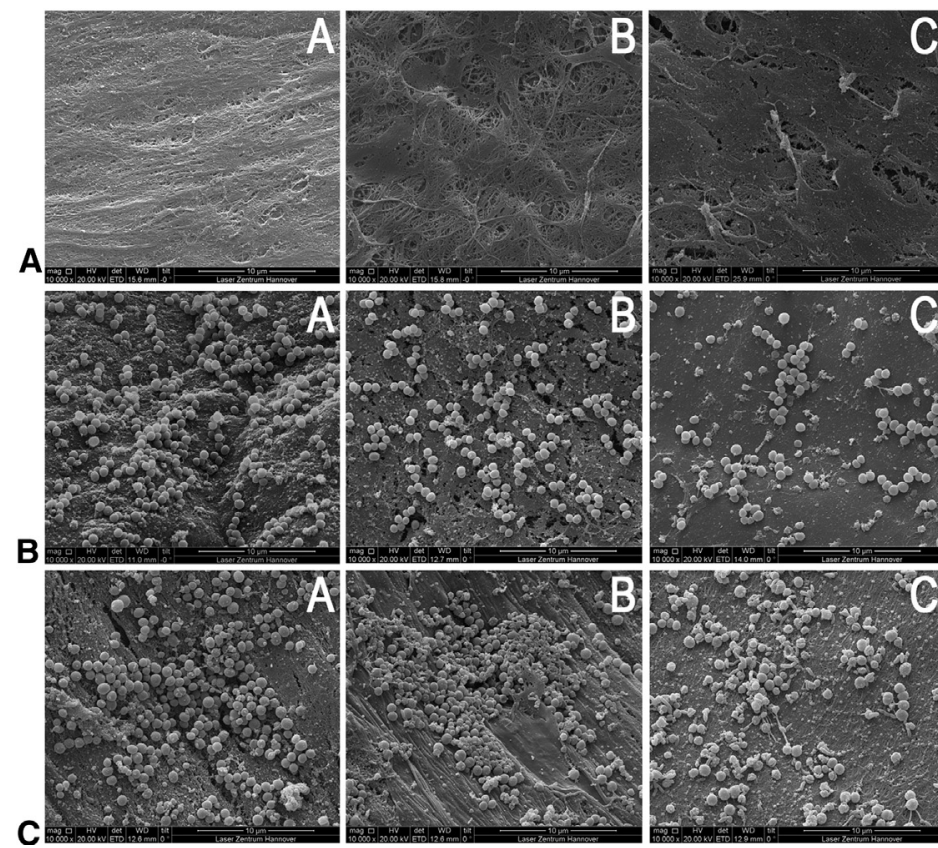

Control
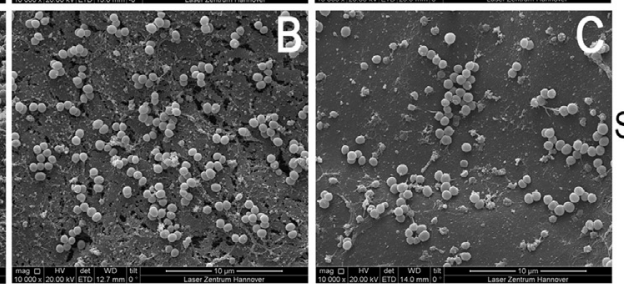

S. epidermidis
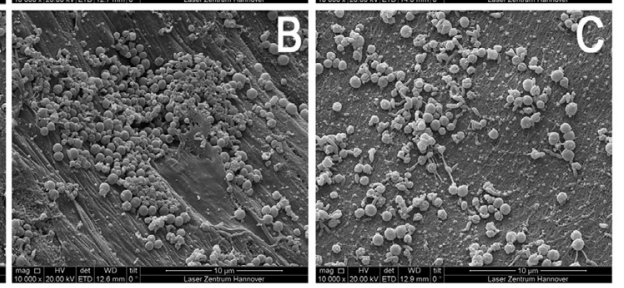

FIGURE 5. Cryopreserved aortic valve tissue after antibiotic treatment according to protocol $A$ through $C$ in $A$, control and after incubation with B, Staphylococcus epidermis (S. epidermidis) or C, Staphylococcus aureus (S. aureus).

A compared with group B or group C. The antibiotics of group A only differed from that of group B with respect to the use of vancomycin instead of flucloxacillin. König and colleagues ${ }^{27}$ showed that high inocula of $S$ epidermidis $\left(1 \times 10^{7} \mathrm{CFU} / \mathrm{mL}\right)$ only moderately affect the activity of flucloxacillin, whereas a compromising effect on glycopeptides has been observed. Consequently, we presume that CHAs stored in antibiotics containing flucloxacillin instead of vancomycin (as a glycopeptide) have an enhanced antibacterial effect against the employed high inocula of $S$ epidermidis $\left(6 \times 10^{7} \mathrm{CFU} / \mathrm{mL}\right)$. According to König and colleagues, ${ }^{27}$ vancomycin has a decreased effect on high inocula of S epidermidis and thus results in an adhering biofilm, which entails a further loss in the antibiotic activity of vancomycin compared with flucloxacillin. Group C also contained vancomycin, but the amount of S epidermidis was significantly smaller compared with the CHAs of group A. This may be related to the different antibiotic compositions.

Third, our microbiologic data, apart from the peculiarity of $S$ epidermidis in group $\mathrm{A}$, reveal a significant antimicrobial activity of cryopreserved aortic vessels, with a tendency toward reduced infection resistance against $P$ aeruginosa. Similar findings have been reported by Camiade and colleagues, ${ }^{19}$ who investigated the infection resistance of cryopreserved thoracic aortic allografts previously stored in gentamicin, lincomycin, and vancomycin. In their study, ${ }^{19} P$ aeruginosa was the only bacterium not inhibited. Notably, CHAs without antibiotic treatment are highly susceptible to bacterial infection, whereas the reapplication of antibiotic agents after thawing also led to particularly enhanced antimicrobial activity. In our study, the aortic vessels stored in the antibiotics in groups B and $\mathrm{C}$ show significantly enhanced antimicrobial activity; that is, a reduced number of colony forming units against staphylococcal bacteria. CHAs of group B appear to be more resistant to $P$ aeruginosa, whereas group $\mathrm{C}$ showed enhanced resistance against $E$ coli (Figure 3). These significant differences in the quantity of adherent bacteria within the same bacterial strain can predominantly be explained on the basis of the residual activity of the different antibiotic mixtures.

Finally, we observed morphologic changes in the microorganisms, especially of the rod-shaped $E$ coli, which were considerably elongated. Justice and colleagues ${ }^{28}$ described this filamentation as a response to environmental stresses, particularly metabolic changes or antimicrobial therapies, which improves bacterial survival. The inhibition of septation during cell growth results in this elongation. Several studies have attributed the filamentation to B-lactam antibiotics (eg, piperacillin and meropenem) that bind to penicillin-binding protein-3 (by inhibition of penicillinbinding protein-3), particularly at low concentrations. ${ }^{29,30}$ The regional antibiotic release alters bacterial growth without eliminating all adherent bacteria. This could be attributed to the high inocula of microorganisms, a limited antibiotic uptake during processing, or the elongated storage time.

Because the procedure of processing of the 3 groups of CHAs only differed with regard to their antibiotic pretreatment, these results can predominantly be explained 
on the basis of the various antibiotic mixtures and their residual activity in CHAs.

In contrast, infection resistance was hypothesized to be attributable to the viability of CHAs. An improved transfer of immunocompetent cells and antibiotics through the wall might lead to an immune-mediated eradication of infection. ${ }^{18}$ However, the level of viability is a matter of debate. ${ }^{21}$ Mirabet and colleagues ${ }^{31}$ demonstrated wellpreserved viable cells in cardiac valve allografts despite cryopreservation and long-term storage. Endothelial and especially interstitial cells retain the capacity to proliferate in vitro. ${ }^{31}$

However, several studies show conflicting results. Koolbergen and colleagues ${ }^{32}$ found that a reduction in cellularity and a loss of endothelial cells led to almost acellular tissue 1 year after the implantation of CHAs. Moreover, nonimplanted valves exhibited a loss of endothelial cells. Mitchell and colleagues ${ }^{33}$ showed similar results indicating that explanted cryopreserved heart valves are morphologically nonviable, even after only 1 day of implantation. Thus, they are unlikely to have the ability to grow, remodel, or exhibit metabolic functions. ${ }^{33}$ In our study, SEM showed subendothelial fibers in groups A through $\mathrm{C}$, indicating a loss of endothelial cells. This could be related to several factors during the processing and/or our experimental setup irrespective of the used antibiotics. The loss is presumably more pronounced in the cusps than in the aortic wall and might predispose to bacterial colonization, possibly also explaining the increased susceptibility of cusps to staphylococcal bacteria. An intact endothelium is resistant to bacterial colonization ${ }^{34}$; however, the loss of endothelial coverage in groups $\mathrm{A}$ through $\mathrm{C}$ suggests that this protective layer is not the relevant factor in avoiding bacterial adherence to CHAs (Figures 4 and 5).

An improved transfer of immunocompetent cells and antibiotics through the wall might also be responsible for the bacterial resistance, possibly because of at least partially viable tissue. However, our data comparing the CHAs of groups A through $\mathrm{C}$ suggest that the bacterial resistance is dependent on the type of antibiotic pretreatment and is not primarily an intrinsic ability of CHAs.

The clinical use of CHAs in aortic prosthetic valve endocarditis represents a generally accepted treatment. ${ }^{1,2}$ In particular, CHAs are believed to be the best conduit for a destroyed annulus, a frequent complication in $56 \%$ to $100 \%$ of cases associated with prosthetic valve endocarditis predominantly caused by staphylococci ${ }^{35}$ because of their infection resistance. In the presence of a root abscess, the reconstruction of the aortic root can be achieved with allograft aortic valves, because the adhering anterior mitral leaflet can be used to patch defects created by the resection of the abscess. ${ }^{15}$ Concerning the treatment of prosthetic graft infections involving the ascending aorta, CHAs have demonstrated encouraging outcomes with acceptable preoperative mortality and reinfection rates of $0 \%$ to $0.04 \%$. 5,16

However, CHAs also have distinct disadvantages such as their limited availability ${ }^{13}$ and their accelerated degeneration. ${ }^{12,14,15}$ Therefore, alternative grafts are used for the management of per annular expansion of infectious endocarditis. Several authors indicate that the freedom from reinfection or reoperation and late mortality is similar among mechanical composite grafts, biological valve conduits, and CHAs. They conclude that an aggressive debridement and prolonged antibiotic treatment, and not the type of substitute material, are the critical factors in determining clinical outcome. ${ }^{10,11}$ With regard to radical surgical techniques, CHAs might allow a more conservative debridement, which is essential in the mediastinum because of the surrounding vital structures, ${ }^{5}$ particularly because the tested aortic wall specimens of groups $\mathrm{B}$ and $\mathrm{C}$ possess an enhanced infection resistance against the frequent infection-causing staphylococcal bacteria. Nevertheless, the low incidence of graft infections, heterogeneous study populations, diverse therapeutic approaches, and various protocols for CHA processing hinder the comparison of outcomes.

\section{Limitations}

The number of CHAs analyzed in this study was rather small. However, legal requirements restrict the use of CHAs for research. Consequently, we had to employ CHAs that had been stored for $>5$ years and were therefore no longer considered suitable for transplantation. For ethical reasons, we were unable to investigate untreated and fresh human tissue to compare our results. Another shortcoming is that an analysis of residual concentrations of antibiotics in long-term CHAs is still missing. Furthermore, infection resistance was assessed in a static instead of dynamic flow model, neglecting the potential influence of circulation. We are aware that the influence of the whole living organism, and particularly the immune-mediated eradication of infection, cannot be evaluated using our in vitro model.

\section{CONCLUSIONS}

CHAs offer a preventive and reliable treatment option against reinfection. Because their infection resistance depends on the antibiotic combination selected during processing, further investigations concerning this treatment are necessary to improve the antimicrobial activity against frequent and highly virulent infection-causing bacteria. Additional impregnation with antibiotic agents during implantation might offer a further protective procedure for avoiding bacterial adherence to the graft.

\section{Conflict of Interest Statement}

Authors have nothing to disclose with regard to commercial support. 
The authors thank Nina McGuinness for providing language editing and Reiner Gebauer for providing technical assistance in electron microscopy.

\section{References}

1. Habib G, Thuny F, Avierinos JF. Prosthetic valve endocarditis: current approach and therapeutic options. Prog Cardiovasc Dis. 2008;50:274-81.

2. Mahesh B, Angelini G, Caputo M, Jin XY, Bryan A. Prosthetic valve endocarditis. Ann Thorac Surg. 2005;80:1151-8.

3. Coselli JS, Koksoy C, LeMaire SA. Management of thoracic aortic graft infections. Ann Thorac Surg. 1999;67:1990-3.

4. Nataloni M, Pergolini M, Rescigno G, Mocchegiani R. Prosthetic valve endocarditis. J Cardiovasc Med (Hagerstown). 2010;11:869-83.

5. Khaladj N, Pichlmaier U, Stachmann A, Peterss S, Reichelt A, Hagl C, et al. Cryopreserved human allografts (homografts) for the management of graft infections in the ascending aortic position extending to the arch. Eur $J$ Cardiothorac Surg. 2013;43:1170-5.

6. Bisdas T, Bredt M, Pichlmaier M, Aper T, Wilhelmi M, Bisdas S, et al. Eight-year experience with cryopreserved arterial homografts for the in situ reconstruction of abdominal aortic infections. $J$ Vasc Surg. 2010;52:323-30.

7. LeMaire SA, Coselli JS. Options for managing infected ascending aortic grafts. $J$ Thorac Cardiovasc Surg. 2007;134:839-43.

8. Tossios P, Karatzopoulos A, Tsagakis K, Sapalidis K, Grosomanidis V, Kalogera A, et al. Treatment of infected thoracic aortic prosthetic grafts with the in situ preservation strategy: a review of its history, surgical technique, and results. Heart Lung Circ. 2014;23:24-31.

9. Czerny M, von Allmen R, Opfermann P, Sodeck G, Dick F, Stellmes A, et al. Self-made pericardial tube graft: a new surgical concept for treatment of graft infections after thoracic and abdominal aortic procedures. Ann Thorac Surg. 2011:92:1657-62

10. Leyh RG, Knobloch K, Hagl C, Ruhparwar A, Fischer S, Kofidis T, et al. Replacement of the aortic root for acute prosthetic valve endocarditis: prosthetic composite versus aortic allograft root replacement. J Thorac Cardiovasc Surg. 2004; 127:1416-20.

11. Jassar AS, Bavaria JE, Szeto WY, Moeller PJ, Maniaci J, Milewski RK, et al. Graft selection for aortic root replacement in complex active endocarditis: does it matter? Ann Thorac Surg. 2012;93:480-7.

12. Fukushima S, Tesar PJ, Pearse B, Jalali H, Sparks L, Fraser JF, et al. Long-term clinical outcomes after aortic valve replacement using cryopreserved aortic allograft. J Thorac Cardiovasc Surg. 2014;148:65-72.

13. Vogt PR. Arterial allografts in treating aortic graft infections: something old, something new. Semin Vasc Surg. 2011;24:227-33.

14. O'Brien MF, Harrocks S, Stafford EG, Gardner MA, Pohlner PG, Tesar PJ, et al. The homograft aortic valve: a 29 -year, $99.3 \%$ follow up of 1,022 valve replacements. J Heart Valve Dis. 2001;10:334-44.

15. Musci M, Weng Y, Hubler M, Amiri A, Pasic M, Kosky S, et al. Homograft aortic root replacement in native or prosthetic active infective endocarditis: twenty-year single-center experience. J Thorac Cardiovasc Surg. 2010;139: 665-73.

16. Lytle BW, Sabik JF, Blackstone EH, Svensson LG, Pettersson GB, Cosgrove DM III. Reoperative cryopreserved root and ascending aorta replacement for acute aortic prosthetic valve endocarditis. Ann Thorac Surg. 2002;74:1754-7.

17. Svensson LG, Adams DH, Bonow RO, Kouchoukos NT, Miller DC, O'Gara PT, et al. Aortic valve and ascending aorta guidelines for management and quality measures. Ann Thorac Surg. 2013;95:1-66.
18. Vogt PR, Brunner-LaRocca HP, Lachat M, Ruef C, Turina MI. Technical details with the use of cryopreserved arterial allografts for aortic infection: influence on early and midterm mortality. J Vasc Surg. 2002;35:80-6.

19. Camiade C, Goldschmidt P, Koskas F, Ricco JB, Jarraya M, Gerota J, et al. Optimization of the resistance of arterial allografts to infection: comparative study with synthetic prostheses. Ann Vasc Surg. 2001;15:186-96.

20. Kuehn C, Graf K, Mashaqi B, Pichlmaier M, Heuer W, Hilfiker A, et al, Prevention of early vascular graft infection using regional antibiotic release. $J$ Surg Res. 2010;164:185-91.

21. Yap CH, Yii M. Allograft aortic valve replacement in the adult: a review. Heart Lung Circ. 2004;13:41-51.

22. Heng WL, Albrecht H, Chiappini P, Lim YP, Manning L. International hear valve bank survey: a review of processing practices and activity outcomes. $J$ Transplant. 2013;2013:163150.

23. Buzzi M, Guarino A, Gatto C, Manara S, Dainese L, Polvani G, et al. Residual antibiotics in decontaminated human cardiovascular tissues intended for transplantation and risk of falsely negative microbiological analyses. PLoS One. 2014;9:e112679.

24. Jashari R, Faucon F, Hoeck BV, Gelas SD, Fan Y, Vandenbulcke S. Determination of residual antibiotics in cryopreserved heart valve allografts. Transfus Med Hemother. 2011;38:379-86.

25. Zander J, Maier B, Zoller M, Dobbeler G, Frey L, Teupser D, et al. Effects of biobanking conditions on six antibiotic substances in human serum assessed by a novel evaluation protocol. Clin Chem Lab Med. July 21, 2015 [Epub ahead of print].

26. Nickolai DJ, Lammel CJ, Byford BA, Morris JH, Kaplan EB, Hadley WK, et al. Effects of storage temperature and $\mathrm{pH}$ on the stability of eleven beta-lactam antibiotics in MIC trays. J Clin Microbiol. 1985;21:366-70.

27. König C, Schwank S, Blaser J. Factors compromising antibiotic activity agains biofilms of staphylococcus epidermidis. Eur J Clin Microbiol Infect Dis. 2001; 20:20-6.

28. Justice SS, Hunstad DA, Cegelski L, Hultgren SJ. Morphological plasticity as a bacterial survival strategy. Nat Rev Microbiol. 2008;6:162-8.

29. Gottfredsson M, Erlendsdottir H, Sigfusson A, Gudmundsson S. Characteristics and dynamics of bacterial populations during postantibiotic effect determined by flow cytometry. Antimicrob Agents Chemother. 1998;42:1005-11.

30. Crosby HA, Bion JF, Penn CW, Elliott TS. Antibiotic-induced release of endotoxin from bacteria in vitro. $J$ Med Microbiol. 1994;40:23-30.

31. Mirabet V, Carda C, Solves P, Novella-Maestre E, Carbonell-Uberos F, Caffarena JM, et al. Long-term storage in liquid nitrogen does not affect cell viability in cardiac valve allografts. Cryobiology. 2008;57:113-21.

32. Koolbergen DR, Hazekamp MG, de Heer E, Bruggemans EF, Huysmans HA, Dion RA, et al. The pathology of fresh and cryopreserved homograft heart valves: an analysis of forty explanted homograft valves. J Thorac Cardiovasc Surg. 2002;124:689-97.

33. Mitchell RN, Jonas RA, Schoen FJ. Pathology of explanted cryopreserved allograft heart valves: comparison with aortic valves from orthotopic heart transplants. J Thorac Cardiovasc Surg. 1998;115:118-27.

34. Thiene G, Basso C. Pathology and pathogenesis of infective endocarditis in native heart valves. Cardiovasc Pathol. 2006;15:256-63.

35. Anguera I, Miro JM, San Roman JA, de Alarcon A, Anguita M, Almirante B, et al. Periannular complications in infective endocarditis involving prosthetic aortic valves. Am J Cardiol. 2006;98:1261-8.

Key Words: ascending aorta, aortic valve, bacterial infection, cryopreserved human allograft, infective endocarditis, prosthetic graft infection 